\title{
Collaborative Research in Art, Design and New Media - Challenges and Opportunities
}

Liggett S., Heald, K., Earnshaw R.A., Thompson E. and Excell P.S.

This is a paper presented at the Internet Technologies and Applications (ITA 2015), 8-11 Sept 2015, Glyndŵwr University, Wrexham, UK.

Copyright of the author(s). Reproduced here with their permission and the permission of the conference organisers.

\section{Recommended citation:}

Liggett S., Heald, K., Earnshaw R.A., Thompson E. and Excell P.S. (2015) 'Collaborative Research in Art, Design and New Media - Challenges and Opportunities', Proceedings of Internet Technologies and Applications (ITA 2015), 8-11 Sept 2015, Glyndŵr University, Wrexham, UK. doi: 10.1109/ITechA.2015.7317456 


\title{
Collaborative Research in Art, Design and New Media - Challenges and Opportunities
}

\author{
S. Liggett ${ }^{1}$, K. Heald ${ }^{2}$, R. A. Earnshaw ${ }^{1}$, E. Thompson ${ }^{1}$ and P.S. Excell ${ }^{1}$ \\ ${ }^{1}$ Glyndwr University \\ \{s.liggett, r.earnshaw, e.thompson, p.excell\}@glyndwr.ac.uk \\ ${ }^{2}$ Bangor University \\ karen_heald@hotmail.com
}

\begin{abstract}
Collaboration between the arts and the sciences has a long history of tension and antipathy, and also, paradoxically, interdependence. Artists such as Leonardo da Vinci were involved with the creation of artistic works and also novel inventions that were intended to serve a purpose in the natural world. More recently the rapid advances of technology have facilitated both the collaboration of artists in virtual spaces and the use of the technology to create, view, and interact with artistic works. Technology and applications are changing the way ideas are formed and the way research is developed and advanced. In addition, the ubiquity of technology has facilitated the rise of social media and its use to support and develop a number of application domains. This paper explores the relationship between creativity, technology, and artistic works, and their interaction and interplay with social media.
\end{abstract}

Keywords: collaboration, interdisciplinarity, models of creativity, innovation in art and design, social media

\section{Creativity and Interdisciplinarity}

\subsection{Ancient Civilisations}

Ancient civilisations such as Greece and China appear to have lacked the concept of creativity. They saw art as a form of imitation or discovery rather than creation, as the latter was assumed to be the province of the sacred or the divine. Seeing creativity in a more pragmatic way as a process of the human mind did not gain widespread acceptance until the Renaissance and the Age of Enlightenment. This also became associated with the development of the scientific method and the systematic discovery of the way the natural world works. The scientific method involved experiment, analysis, and the construction of theories capable of making predictions about future observations.

Various models of creativity and inspiration have been formulated in order to better understand the creative process. Some of these involve elements such as imagination, intuition, integration, convergence and divergence. In addition, where the creative processes involve a number of people, there is a need to consider how best to organise such processes to yield the best results.

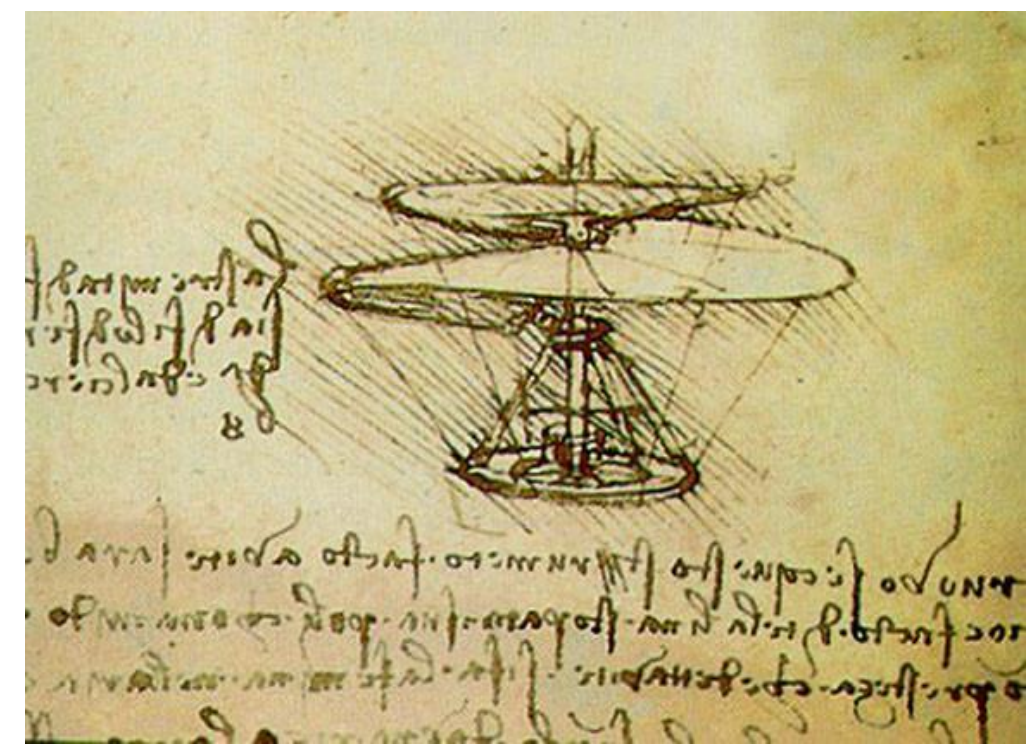

Fig. 1. Leonardo da Vinci's Aerial Screw (precursor to the modern helicopter) 
It is worth noting that Leonardo da Vinci in the $15^{\text {th }}$ century was involved with both the creation of artistic works (e.g. the Mona Lisa) and also novel inventions that served a purpose in the natural world (e.g. the aerial screw - see Fig. 1)

This is an indication that creative genius can transcend the traditional boundaries between disciplines. In addition, it is often at the boundaries between existing disciplines that new disciplines develop, because they contain some of the elements from more than one discipline. This also suggests that the current boundaries between disciplines may be somewhat arbitrary and based on accumulated past knowledge rather than future knowledge. One consequence of this basis in past knowledge is the development of traditions in a discipline which can make it difficult to make significant revolutionary advances. Incremental advances tend to be preferred because they can be more readily accommodated within the current traditions and frameworks of understanding. Wilson [1] presents the case for an interdisciplinary approach in order to be able to solve the complex and intractable problems in today's world.

\subsection{Current Developments}

Catmull [2] describes how to achieve an optimum coalescence of art, innovation and business arising from his experience as president of Pixar. Hegarty [3] presents the view that everyone can be creative. It is more a matter of individual context and approach rather than conformance with rules. Shiu [4] notes the interdisciplinarity of creativity research.

The arts and sciences were earlier regarded (e.g. Snow [5]) as operating within different paradigms of understanding making communication across the divide very difficult, if not impossible. However, there are increasing trends to greater mutual understanding based on a fuller appreciation of the mutual benefits. Disciplinary silos may be increasingly regarded as an historical relic, dependent more upon history and context, rather than being able to respond effectively to the opportunities presented by current challenges in the arts, science, and technology.

In addition, creative and interdisciplinary thinkers have abilities that are being increasingly recognised and valued in a range of activities including business, research, and the media.

\section{Collaborative Research and Development}

"Nothing new that is really interesting comes without collaboration," James D. Watson, codiscoverer of the double helix, 1953.

\subsection{Collaboration across Discipline Boundaries}

Where a variety of inputs is needed from different disciplines in order to further a research area, then mechanisms for collaboration are necessary. In addition, the norms, concepts, and practices of research in each discipline need to be understood across the boundary.

Multi-disciplinary, inter-disciplinary, and trans-disciplinary research are identified by Holzbaur et al as different aspects of collaboration across boundaries [6].

The emergence of new disciplines at the boundaries between existing disciplines is particularly relevant for computer science and its interaction with other disciplines, and for art and design and its interaction with science, technology, and medical areas. Thus research across the boundaries is important for the future. In addition, such research areas tend to be applicable, that is, they have relevance for real-world applications and finding solutions to current problems.

Cognitive diversity enables groups to find better solutions and also facilitates finding solutions when the problems are complex. Thus collaboration across discipline boundaries may yield more groundbreaking results than collaboration within a discipline. 


\subsection{Design Education}

The rate of change of interdisciplinary knowledge has implications for educational curricula and educational systems. Such knowledge is necessary in order to address complex and difficult problems. Thus the next generation needs appropriate training to give them skills and expertise to address them. Yet only slow progress is being made [1].

"Evidence suggests that transformational innovation occurs at the intersection of multiple disciplines rather than isolated within them. Design - being both pervasive and inherently interdisciplinary - has the power to transcend many disciplines and help break down the departmental "silos" that hinder such collaborative efforts. Many universities are now struggling to embrace the curricular innovations that are necessary to achieve and sustain interdisciplinary education" [7].

\section{Art and Design, New Media and Collaboration}

\subsection{Art-Science Collaboration}

Art Schools are increasingly seeking to encourage collaboration across disciplines in recognition of the concept that art and design is a subject that is at the heart of society. All history may be regarded as the history of ideas. The arts have a responsibility to open up new fields of consciousness and formulate ideas that are able to provide synergistic connections between arts, science, technology, business and society.

The Angerwandte (University of Applied Arts, Vienna) links artistic and scientific disciplines. In 2012 it opened departments in art and science and TransArts that encourage different cognitive abilities and research methods to investigate new research ideas. In the UK, the Wellcome Trust has for many years recognised the importance of synergies between art and science and their Arts Award supports artists to create new work that critically engages audiences with biomedical science. It is believed that artists have a distinctive approach to understanding and communicating ideas that can illuminate and challenge perceptions within society. This Arts Award has been important in supporting collaborative research between artists and scientists, and encouraging artists to look to scientific research as inspiration for their work.

There is a growing science/art research activity in the UK. In 2013, the Wellcome Trust funded a project 'Fun With Cancer Patients: Fierce', in which artists collaborated with a paediatric oncologist at Birmingham Children's Hospital, a psychologist of University College, London, and the Teenage Cancer Trust, to explore the psychosocial and medical realities of teenagers undergoing, or having undergone, cancer treatment. A final exhibition of work was exhibited at the Fierce Festival, Birmingham in 2013.

In North Wales, artists Karen Heald and Susan Liggett collaborated on an arts/science R\&D funded project with NHS consultant psychiatrists. The study involved the artists working with patients to create artworks using video for exhibition [8]. This collaborative approach to research into mental health, using digital media, is innovative and unique to research in the field of psychiatry. The synthesis of collaborative arts and science practice describes 'in-between-ness' as a system, which allows both an interdisciplinary and multidisciplinary methodology, and for these two different disciplines to meet through its approaches and media. As such, the research methodology moves between different modes, responding uniquely to the qualities of individual artists, scientists, institutions and technologies.

This research project builds on experience over several years of the arts in health projects across the Betsi Cadwaladr University Health Board. This has supported professional artists in residence in a variety of health care settings across North Wales. The project was also inspired by previous studies using photography as a means to explore personal authenticity in children being treated with stimulants for Attention Deficit Hyperactivity Disorder (ADHD) [9]. In addition to the aims of the psychiatrists, the artists were keen to explore the role of preverbal language and creativity for patients navigating the "in-between-ness" from depression to recovery. 
Recent research has shown that treatment of depression with antidepressants produces changes in emotional processing [10]. These changes allow the prediction of clinical recovery from depression. The significance of this work is set in the context of rapidly expanding knowledge of how the brain processes emotional stimuli; how these processes are affected by depression, and how these processes change in response to treatment. To date, these changes have been investigated using very specific psychological tasks. However, it is still unclear to what degree depression, recovery and antidepressants affect a range of psychological processes, and ultimately how the experience of the patient changes during treatment. To inform future directions of research in this area, this innovative arts/science collaboration explores experiential changes during treatment with antidepressants.

Although the project was conceived as a method of exploring the experiential effects of antidepressant medication, these preliminary findings raise the possibility that engagement in the creative process itself may aid recovery from depression. This may be through diverting attention from internal ruminations towards external sensations, enhancing self-worth through the creation of aesthetic work, and promoting the reconstruction of a meaningful personal narrative.

The artists perceived these abstract and poetic non-linear narratives as "dream films", which may be regarded as a transitional space where contextualisation begins to re-emerge (Fig. 2). The relative contributions of medication and interactions with professional artists to this recovery are not easy to disaggregate in this project. The project generates potentially testable hypotheses for future research into the psychological effects of antidepressants, and also points toward clinical studies investigating the role of creativity in recovery from depression. Such future work would also benefit from the collaborative approach adopted in this project that respected and valued the creative space developed and nurtured by the artistic partners. It is also important to be able to verify that it is the actual creative processes that are having an effect on the mental states of patients, rather than just being a placebo effect, i.e. the procedure rather than the content of the procedure causes the change. To this end, it is important to put in place controlled trials where any placebo effects can be analysed and eliminated.

It is hoped that the results of the artists' collaboration with scientists will result in important insights into the process of recovery from depression from a scientific perspective, but there are also many potential creative avenues to explore. By analysing both the artists' individual creative processes, as well as the participants' creative processes, insights can be gained into the creative process itself. Artistic contemplation differs from the theoretical contemplation of the scientific intelligence in cherishing an interest in objects in their individuality. It does not preoccupy itself in reducing them, or relating them, to more universal principles or conceptions. 


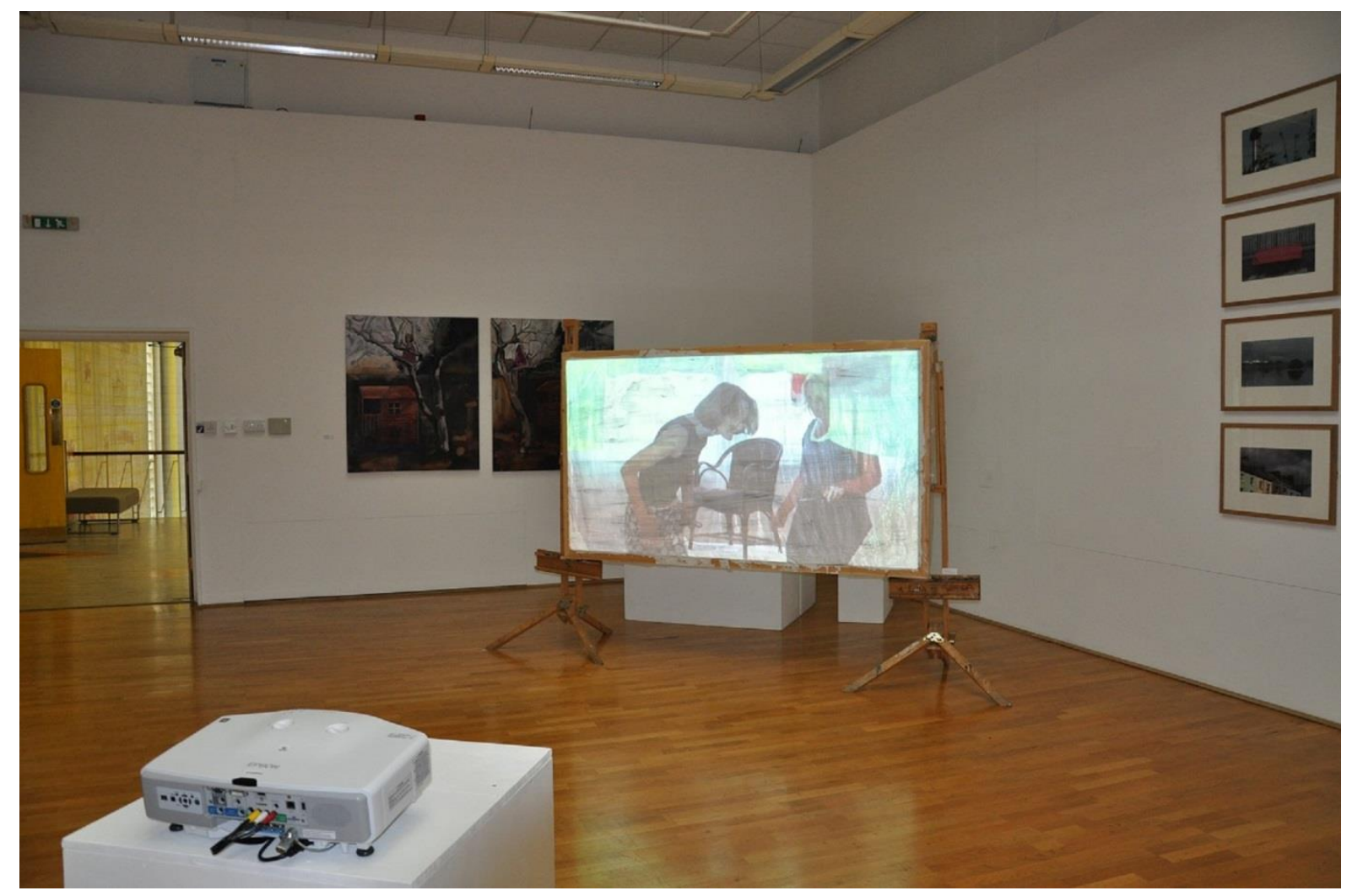

Fig. 2. In-between-ness exhibition, Oriel Sycharth, Glyndwr University 2013

\subsection{Social Media}

The utilisation of various forms of social media such as Facebook and Twitter by artists has increased the potential for bringing artworks to wider and more varied audiences, as well as new kinds of audiences for whom creative works may be an entirely new experience. The levelling effect social media has on the human landscape has also enabled artists to bring their work to the attention of curators through self-promotion rather than waiting to be discovered - before they are able to exhibit their work. No longer bound by the constraints of the traditional gallery system, commercial galleries are now looking to artist-run initiatives in non- traditional venues for new talent. Hierarchical constraints are relaxing as painters side-step traditional routes to success and initiate and curate wellconceived shows with other artists. The use of social media has assisted in the building of mutual relationships with other artists. They are not focussing on the commercial galleries to the same extent as previously to validate their credibility as artists. There are numerous examples of this activity in the UK and two examples have been included here which impact on contemporary painting practice.

\section{Pluspace}

Pluspace is a curatorial project which is the work of Matthew Macauley, a painter and recent graduate from Coventry University. Plusspace is a voluntary artist-run organisation set up in 2011 to promote contemporary painting. Mccauley was dissatisfied with the lack of space and opportunities to show and develop painting practices for artists in Coventry and its environs. In June 2014 an exhibition was curated entitled 'a dream within a dream' at the Banksley Gallery - a space run by the artist in Manchester to invite six painters from across the UK who are being followed on Twitter. Claudia Bose was one of the artists included in the space. Twitter was used to engage in dialogue with other painters. Her Twitter activity has resulted in meeting several artists and curators including Macauley, which has been important for practice as an abstract painter, and in ensuring the work is located within the critical framework that exists between other abstract painters in the UK.

"The painting of Claudia Böse show careful through and process-led considerations around form in her exploration of the medium. Bose focuses on contained area created by framing devices, inspired by the domestic and everyday life, screens, table mats, and windows 
amongst others. These paintings incorporate influences form place, history and nature, creating a new interpretation of these ideas through an abstract language". (Castlefield Gallery [11])

Having exhibited at the show, Claudia Bose was also invited to join a further Manchester-based painting exhibition titled About Painting curated by the painter Lisa Denyer, at the Castlefield Gallery's new Art Space. A contact was made with Lisas Denyer through Twitter. Both these exhibitions were very specifically curated to promote contemporary abstract painting in the UK.

"The paintings range from the highly structured and pre-planned, to pieces showing a freer and more spontaneous language. I'm interested in the capacity that abstract painting has to represent a multitude of thoughts, feelings and points of recognition through variances in visual language and openness to interpretation, so I wanted to explore this through the work in the show." (Castlefield Gallery [11])

Using Twitter, Bose's work is being promoted within the context of contemporary abstract painting and the exposure of these exhibitions feeds into the interest in abstract painting in the UK. A renewed interest in the genre is taking place as evidenced in the critically acclaimed online journal Abstract Critical which provides a forum for serious and ambitious abstract art. The journal website is interactive and features news, reviews of exhibitions and articles written surrounding current debates on contemporary abstract art and practicing artists contribute to the site with essays and articles [12].

\section{detail}

In 2014, artist curator and academic Andrew Bracey received funding from the Arts Council England and University of Lincoln to curate an art exhibition titled (detail) which featured the work of 118 international painters. Each artist was invited to exhibit a selected close-up from one of their paintings. The details were then printed and displayed to give a glimpse of each artwork in reproduction and to create a huge collage of images for Bracey to curate. The exhibition was first displayed at H-Project Space in Bangkok in July 2014, before being reinstalled at the Transition Gallery in London in October and the Usher Gallery in Lincoln December, 2014. The H Gallery is one of Asia's leading art venues that has a focus on emerging Asian artists with a program of exhibitions and installations that aim to generate critical dialogues on contemporary art practices in a global context. Each exhibition of detail was displayed differently in response to the unique aspects of each gallery setting. The details of the paintings when viewed en masse formed a collage of juxtaposed images. The exhibition featured a wide range of painters from the UK, including well established and recent graduates. The work displayed comprises a snapshot which highlights the current concerns of contemporary painters - including abstraction, landscape, figurative, expanded field and conceptually driven practices. Also the featured artists use a wide variety of paint media, including oil, gouache, watercolour, acrylic, ink and pigmented silicone [13].

The exhibition's curator summarises this as follows -

"In the studio I have found my own relationship to working on a painting is up close to it, with only occasional glimpses of the whole as I step back. This focus on this particular painter's viewpoint of the painting provoked the idea for this exhibition. This exhibition is an attempt to bring this studio mentality to the gallery. There is a power in the detail, it offers up fresh possibilities for viewing painting" (Figure 3) [14]. 


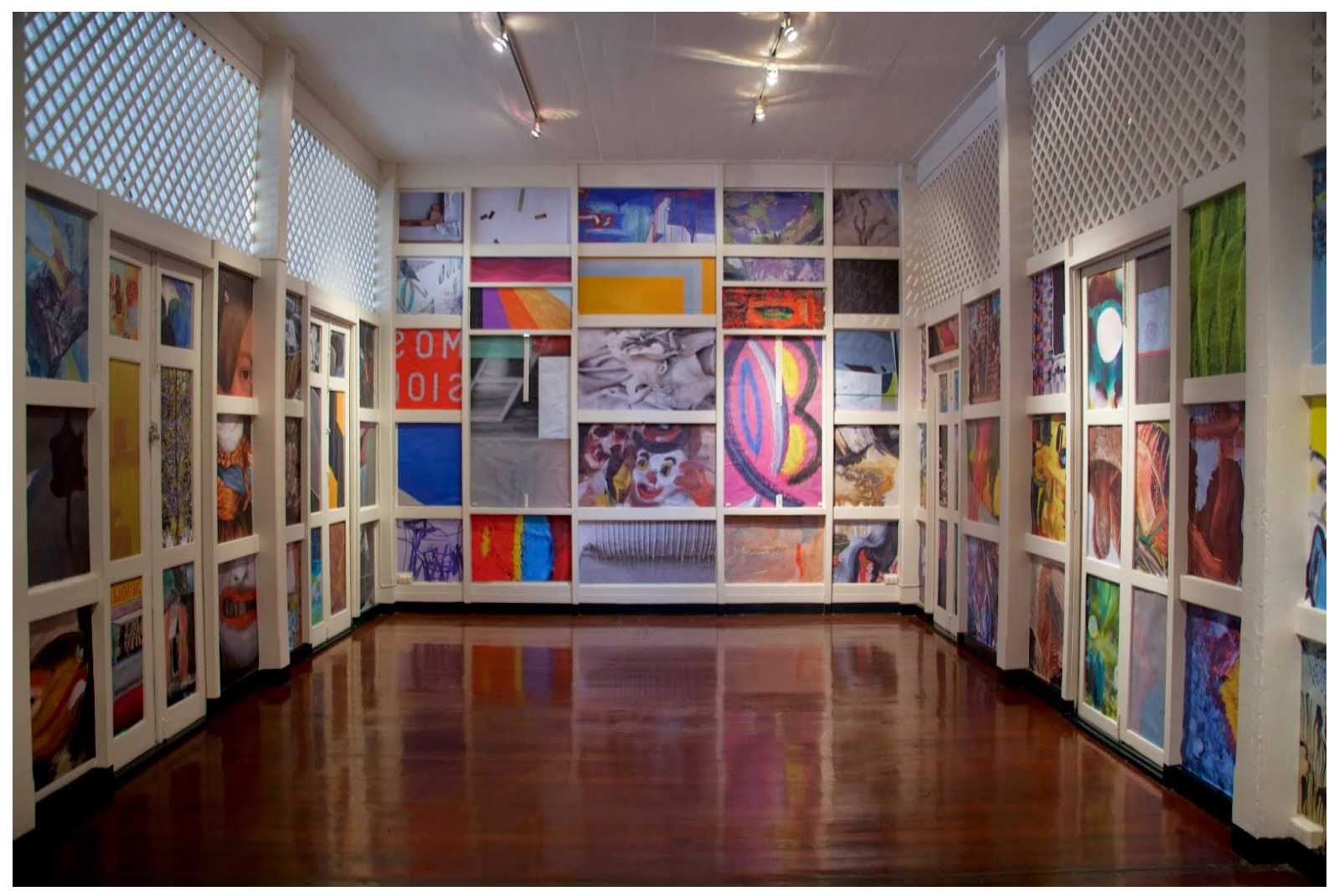

Fig. 3. Installation H-Project Space, Bangkok, July 2014 (Credit: Andrew Bracey)

\section{Conclusions}

Collaboration brings new ideas and new opportunities, as well as new challenges. Creativity thrives on the opportunity to re-frame, re-examine, re-analyse and reflect. New technology is blurring the distinction between real and virtual. Thus creative works, exhibitions, and interactions are no longer constrained to a particular place, at a particular time, with a particular group of people in a particular social context. Social media allows and facilitates one-to-many communications and many-to-many communications. This opens up new dimensions of participation, observation, and interaction giving rise to new perceptions, new understandings, and new forms of expression. Its effect is therefore transformative. Given that the Internet and social media are still in their relative infancy, the potential for the future is immense.

\section{References}

[1] A. G. Wilson, "Knowledge Power; Interdisciplinary Education for a Complex World", Routledge, pp 169, 2010

[2] E. Catmull, "Creativity, Inc.: Overcoming the Unseen Forces That Stand in the Way of True Inspiration", Bantam Press, pp 368, 2014.

[3] J. Hegarty, "Hegarty on Creativity: There are no Rules", Thames and Hudson, pp 128, 2014.

[4] E. Shiu (Ed), "Creativity Research: An Inter-Disciplinary and Multi-Disciplinary Research Handbook", (Ed), Routledge, pp 356, 2014.

[5] C. P. Snow, “The Two Cultures”, London: Cambridge University Press, 1959. 
[6] U. D. Holzbaur, L. O. K. Lategan, K. Dyason, D. Kokt, "Seven Imperatives for Research" SunMedia Bloemfontein, ISBN 978-1-920382-13-1, 2012

[7] T. W. Simpson, M. Parkinson, D. Celento, W. Chen, A. McKenna, E. Colgate, D. Norman, P. Papalambros, R. Gonzalez, B. Roth, L. Leifer, "Navigating the barriers to interdisciplinary design education: Lessons learned from the NSF Design Workshop Series”, Proceedings of the ASME Design Engineering Technical Conference. 2010;6:627-637, 2010

[8] Art Exhibition, Bangor, 2010-13, http://www.rcpsych.ac.uk/pdf/Art\%20exhibition.pdf

[9] I. Singh, "Clinical implications of ethical concepts: moral selfunderstandings in children taking methylphenidate for ADHD", Clinical Child Psychology \& Psychiatry. 12(2):16782, 2007.

[10] R. Tranter, D. Bell, P. Gutting, C. Harmer, D. Healy, I.M. Anderson, "The effect of serotonergic and noradrenergic antidepressants on face emotion processing in depressed patients”. J Affect Disord, 118, 87-93, 2009.

[11] Castlefield Gallery http://www.castlefieldgallery.co.uk/event/launch-pad-aboutpainting/\#sthash.hLqsc0cU.dpuf )

http://www.castlefieldgallery.co.uk/event/launch-pad-about-painting/

[12] Abstract Critical - http://abstractcritical.com/

[13] H Gallery - http://www.hgallerybkk.com/Exhibitions/exhibition-event.php?id=58

[14] Transition Gallery - http://www.transitiongallery.co.uk/htmlpages/\%28detail\%29.html

\section{Biographies}

\section{Dr Susan Liggett}

Susan Liggett is a practising painter and Reader in Fine Art at Glyndwor University. She has a PhD from the University of Wales (2008), a Post Graduate Diploma in Painting (MA) from the Royal Academy Schools London (1994) and a BA (Hons) from Nottingham Trent University (1989). Her work explores personal memory within the genres of landscape, figure and still life painting. She also works on collaborative research projects using performance and film that investigates applications of the creative process.

www.Susanliggett.com

www.suite-studiogroup.co.uk

\section{Dr Karen Heald}

Karen Heald is an artist, experimental filmmaker, an Honorary Research Fellow in Social Sciences and Lecturer in Fine Art at Bangor University. She has a practice-based PhD (2014), an MA in Contemporary Fine Art from Leeds Metropolitan University and a BA (Hons) in Visual Arts from the University of Salford. Her research explores in-between-ness through time, creativity and its relationship to video, site-specificity, and the philosophical complexities of arts and science collaborations.

www.karenhheald.co.uk

\section{Prof Rae Earnshaw}

Rae Earnshaw is Professor of Creative Industries at Glyndwr University. He gained his $\mathrm{PhD}$ at the University of Leeds. He was Dean of the School of Informatics at the University of Bradford (1999- 
2007) and Pro Vice-Chancellor (Strategic Systems Development) (2004-09). He has been a Visiting Professor at Illinois Institute of Technology, George Washington University, USA, and Northwestern Polytechnical University, China. He is a member of ACM, IEEE, CGS, and a Fellow of the British Computer Society and the Institute of Physics, and a recipient of the Silver Core Award from the International Federation for Information Processing, Austria. He has authored and edited 36 books on computer graphics, visualization, multimedia, art, design, and digital media, and published over 200 papers in these areas.

http://sites.google.com/site/raearnshaw/

\section{Prof Estelle Thompson}

$<<$ Estelle to add biography

\section{Prof Peter Excell}

Peter Excell is Deputy Vice-Chancellor and Professor of Communications at Glyndwr University. His interests cover computing, electronics, and creative industries, with a strong spirit of interdisciplinarity that is needed for the digital knowledge economy. He gained his BSc in Engineering Science at the University of Reading and $\mathrm{PhD}$ in Electronic Engineering at the University of Bradford. His work on future mobile communications devices is being carried out in conjunction with colleagues from wider discipline areas, analysing human communications in a holistic way and developing new ways of using mobile multimedia devices. He has published over 400 papers. He is a Fellow of the British Computer Society, the Institution of Engineering \& Technology and of the Higher Education Academy, a Chartered IT Professional and Chartered Engineer.

Heald and Liggett's recent collaborative exhibitions include: In-Between-ness- Oriel Sycharth, Wrexham, 2013, Videoformes, Trinity Church, Salford (2012); The Vending Machine, Serra dei Giardini and the Contemporary Art Galleria Perela, Venice (2011).

http://www.in-between-ness.co.uk 